\title{
The Zinc, Copper, Manganese, Vanadium, and Iodine Content of Hair from 38 Canadian Neonates
}

\author{
R. S. GIBSON AND M. S. DeWOLFE \\ Departments of Pediatrics and Biochemistry, Dalhousie University, Halifax, Nova Scotia, Canada
}

\begin{abstract}
Summary
Instrumental neutron activation analysis was used to establish "normal values" for the zinc, copper, manganese, vanadium, and iodine concentrations in washed hair samples from Canadian neonates. Sixteen males and 22 females (mean gestation of $\mathbf{4 0} \mathbf{w k}$; mean birthweight $3590 \mathrm{~g}$ ) were included in the study. Their respective mean concentrations \pm SE (parts per million) were 224.0 $\pm 6.29 ; 12.6 \pm 0.61 ; 0.24 \pm 0.04 ; 0.05 \pm 0.01 ; 24.3 \pm 4.76$. All the trace elements were normally distributed. No correlations of hair copper, zinc, and manganese with the variables sex, parity, and maternal socioeconomic status were found.

A positive correlation for zinc with manganese $(0.32 ; P=0.024)$ was apparent, suggesting that the concentrations of these two elements at birth were interrelated.

It is concluded that neonatal hair concentrations of copper, manganese, and vanadium were lower than most reported values for older children and adults. In contrast, the hair zinc concentration of the neonates in this study was higher than that of Denver neonates, and may reflect higher body zinc concentrations, perhaps due to regional differences in the trace metal content of the ground water.
\end{abstract}

\section{Speculation}

The establishment of normal values for the zinc, copper, manganese, vanadium, and iodine concentrations of neonatal hair samples is essential before one can assess whether the hair levels reflect body concentrations at birth. Hair trace metal levels may provide an index for the detection of trace metal deficiencies at birth.

It has been suggested that the trace metal content of hair may reflect the concentration of some trace elements both in animals and man. For example, the zinc content of hair and feathers is generally lower in zinc-deficient animals $(22,25)$ whereas the concentration of manganese in wool is dependent on the dietary intake (21). Significantly lower hair zinc concentrations in zinc deficient male Egyptian dwarfs have been reported $(28,32)$ and extremely low hair copper levels found in infants with severe copper deficiency (12).

Both environmental and surface contamination are known to contribute to the levels of some trace elements in hair $(2,3,11)$ and are, thus, major limitations if hair samples are to be used for the assessment of body trace metal concentrations. Exogenous copper may make a major contribution to the hair copper content after several months of exposure to the external environment. However, this effect can be eliminated by sampling hair close to the scalp (11). Surface contamination can also be effectively removed by employing rigorously controlled washing procedures $(3,15,18)$. Fortunately, contamination effects should be minimal in neonatal hair samples.
The purpose of this investigation was to establish normal values for the zinc, copper, manganese, vanadium, and iodine concentrations of hair in 38 full term healthy Canadian neonates. Levels of these trace metals in hair may reflect body concentrations and, thus, provide an index for the detection of trace metal deficiencies at birth.

There are very little data available on the trace metal concentrations in the hair of newborn infants although some exist for children and adults $(6,7,10,16,17)$. Only small hair samples are available from neonates which makes analysis by atomic absorption, perhaps the most widely used method, difficult. Instrumental neutron activation was chosen for this investigation, being particularly suitable for the nondestructive multielement analysis of small hair samples.

\section{METHODS}

SUBJECTS

The patients were 38 full term healthy infants of mean birthweight of $3590 \mathrm{~g}$ and mean gestational age of $40 \mathrm{wk}$, born in the Grace Maternity Hospital, Halifax, Nova Scotia. Sixteen were male and 22 were female.

\section{MATERIALS AND SAMPLE PREPARATION}

Hair samples, cut close to the scalp at the back of the head were taken $0-3$ days after birth. Individual hair samples weighing approximately $20 \mathrm{mg}$ were placed in acid-washed polyethylene tubes and washed with $15 \mathrm{ml}$ of a $1 \%$ solution of the nonionic detergent, Actinox (34) according to the method of Harrison et al. (18). The detergent solution contained negligible amounts of the analyzed elements and its use in the washing procedure does not contribute to hair trace metal levels $(15,18)$. The tubes were agitated on a mechanical shaker for $\mathbf{3 0} \mathrm{min}$ at room temperature, centrifuged at $1500 \mathrm{rpm}$ for $15 \mathrm{~min}$, the liquid decanted, and discarded. The hair samples were further rinsed four times with distilled, deionized water to insure thorough removal of the detergent. For each rinsing cycle, agitation for $15 \mathrm{~min}$ with $15 \mathrm{ml}$ of deionized water was carried out before centrifugation.

Washed hair samples were placed in small, weighed, acidwashed polyethylene bags of low trace metal content and dried for $22 \mathrm{hr}$ at $55^{\circ} \mathrm{C}$ in an oven. After cooling in a desiccator, the packaged hair samples were sealed and weighed.

Aliquots of a standard reference solution containing known amounts of copper, zinc, manganese, vanadium, and iodine were dried in weighed polyethylene bags. Multiple aliquots from a composite control hair sample were also prepared and two included in each irradiation. This allowed one to assess the reproducibility of the method (Table 1).

Analytical Procedure. The sealed polyethylene sample bags were punctured to remove as much air as possible before irradiation. The hair samples, together with appropriate standards and blank 
Table 1. Summary of zinc, copper, and manganese determinations in 21 aliquots of a control hair sample. Data in ppm.

\begin{tabular}{lccc}
\hline & $\mathrm{Zn}$ & $\mathrm{Cu}$ & $\mathrm{Mn}$ \\
\hline Mean & 112.9 & 19.4 & 0.21 \\
SE & 2.9 & 0.6 & 0.036 \\
95\% confidence interval & $106.9-118.9$ & $18.1-20.8$ & $0.13-0.29$ \\
\hline
\end{tabular}

polyethylene bags were packed into a polyethylene vial $(3.5 \mathrm{~cm}$ long, $1.5 \mathrm{~cm}$ diameter) which was flushed out with nitrogen before sealing. For the determinations of copper, zinc, and manganese, the vial was exposed to a thermal neutron flux of $1 \times 10^{12}$ neutrons $\mathrm{cm}^{-2} \mathrm{~s}^{-1}$ in the inner site of the Dalhousie University Slow Poke Reactor for a period of up to $16 \mathrm{hr}$. Errors introduced by a flux variation from one irradiation to another were eliminated by including a fresh standard with each irradiation.

After a period of $1 \mathrm{hr}$ to allow for the decay of interfering short lived isotopes, principally, ${ }^{41} \mathrm{Ar},{ }^{128} \mathrm{I}$, and ${ }^{80} \mathrm{Br}$, the irradiated samples, standards and blanks were counted on germanium-lithium detectors $(\mathrm{Ge}(\mathrm{Li}))$ with $8 \%$ relative efficiencies and active volumes of $50 \mathrm{cc}$ for periods of 600-1200 seconds depending on the size of the sample. The detectors were each coupled to a 2048 multichannel analyzer.

Spectra were recorded on magnetic tape and analyzed using the photopeak procedure of Routti (29). Half-life corrections were applied to the net peak areas and the results calculated in terms of ppm dry weight. In exceptional cases, during the first few hours after irradiation, ${ }^{128} \mathrm{I}(442.7 \mathrm{keV})$ overlaps ${ }^{69} \mathrm{Zn}(438.7 \mathrm{keV})$. However, the two peaks are entirely resolved by the photopeak procedure (29). Both ${ }^{80} \mathrm{Br}$ and ${ }^{22} \mathrm{Na}$ contribute to the $511.0 \mathrm{keV}$ annihilation peak used for the determination of copper. However, corrections for these interferences were unnecessary as the washing procedure greatly reduced the sodium and bromine content of the hair samples $(3,4)$

Each hair sample was also reirradiated on another occasion for $5 \mathrm{~min}$ at a neutron flux of $10^{12} \mathrm{n} \mathrm{cm}^{-2} \mathrm{~s}^{-1}$ for the determination of iodine and vanadium. After a 1-min decay period, samples were counted for 5 min with a $\mathrm{Ge}(\mathrm{Li})$ detector (relative efficiency $6.4 \%$; active volume $35 \mathrm{cc}$ ) and the $\gamma$-ray spectrum recorded using a Tracor Northern TN-11 Gamma-ray Spectrometer. Spectra were analyzed according to the procedure cited above. To evaluate any leaching effects of the washing procedure, iodine concentrations of both washed and unwashed hair samples were compared and found to be very similar.

\section{RESULTS}

Frequency distributions of the copper, zinc and manganese concentrations in the neonatal hair samples are presented in Figure 1. Application of the Kolmogorov-Smirnov one-sample test showed that the data do not exhibit any significant deviations from normality at the $95 \%$ confidence limit. Descriptive statistics for each of the trace elements determined are shown in Table 2. No correlations of hair copper, zinc, and manganese concentrations with the variables sex, parity, and maternal socioeconomic status were found. In contrast, calculation of Spearman rank correlation coefficients revealed a positive correlation for zinc with manganese $(0.324 ; P=0.024)$.

\section{DISCUSSION}

\section{METHODOLOGY}

Both organic solvents and detergents or shampoos have been shown to be effective in removing surface contamination from hair. For this study, the nonionic detergent procedure of Harrison et al. (18) was chosen due to ease in handling, speed, safety and the availability of nonionic detergent. In addition, Bate (2) and Dyer (4) concluded that this method removed much of the sodium and some bromine from hair; a major advantage when using instrumental neutron activation analysis. These two elements when present in irradiated samples interfere with the determination of short lived isotopes of trace elements such as vanadium and mangasese.

Before the development of neutron activation procedures, most analyses of hair for trace elements were conducted spectrophotometrically. Strain et al. $(31,32)$ employed emission spectrography to analyze hair from twelve United States neonates, zinc-deficient male Egyptian dwarfs and male adults residing in Cairo and New
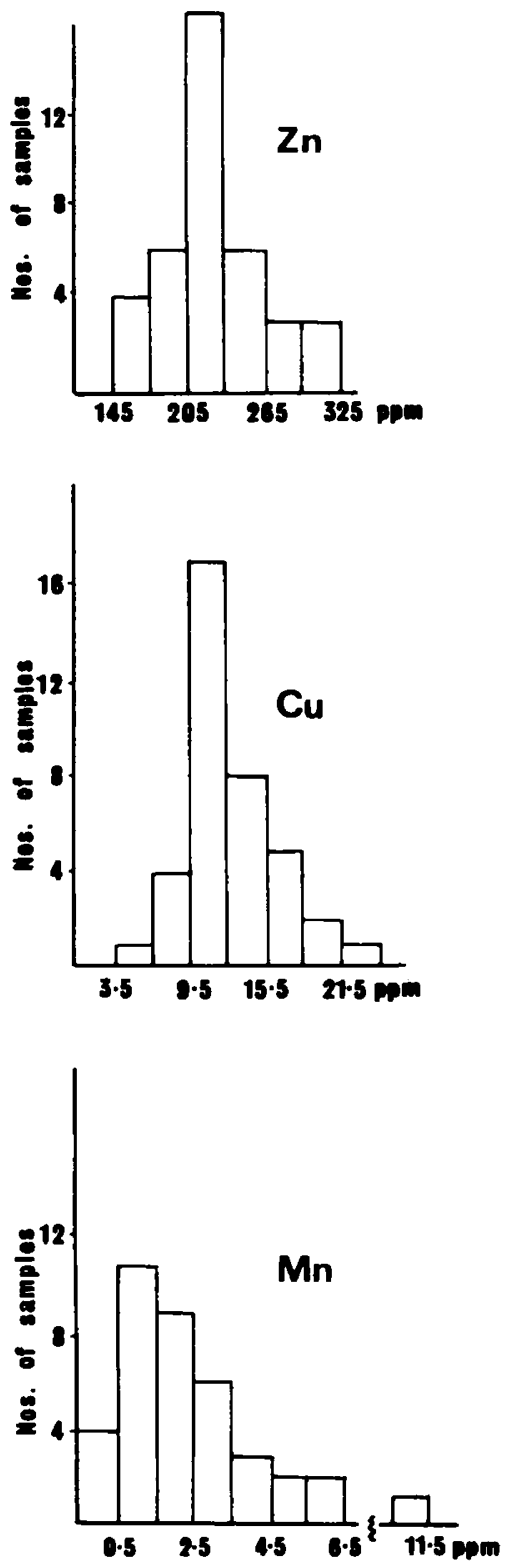

Fig. 1. Frequency distribution of hair zinc, copper, and manganese concentration. Data in ppm.

Table 2. Hair trace element concentrations (parts per million)

\begin{tabular}{lccccc}
\hline & Mean $(n)^{\prime}$ & Median & $\mathrm{SE}$ & $\mathrm{Z}^{2}$ & $\boldsymbol{P}$ \\
\hline Zinc & $224(38)$ & 221 & 6.29 & 0.64 & 0.81 \\
Copper & $12.6(38)$ & 11.2 & 0.61 & 1.04 & 0.23 \\
Manganese & $0.24(38)$ & 0.19 & 0.04 & 0.87 & 0.42 \\
Vanadium & $0.05(16)$ & 0.04 & 0.01 & 1.17 & 0.13 \\
lodine & $24.3(21)$ & 14.55 & 4.76 & 0.97 & 0.30 \\
\hline
\end{tabular}

${ }^{\prime}(n)=$ number of hair samples.

${ }^{2}$ The $\mathrm{Z}$ statistic calculated by the Kolomogorov-Smirnov one-sample test for normality shows that the distribution of all the trace elements determined does not differ significantly from normal. 
York. Atomic absorption spectrophotometry was used both by Klevay $(19,20)$ in his investigations of hair as a biopsy material for assessing zinc and copper nutriture, and Baumslag et al. (5) to study the trace metal content of maternal and neonate hair. However, instrumental neutron activation has many advantages for the analysis of neonatal hair samples. It has low detection limits, is nondestructive and can be used for the determination of several elements simultaneously. Sample preparation and postirradiation handling is minimal, thus, reducing chances of contamination.

\section{NEONATAL HAIR TRACE METAL CONCENTRATIONS}

Liebscher and Smith (23) suggest that a statistically normal distribution of certain trace elements in the tissues is due to the existence of an internal control mechanism which tends to maintain specific concentrations. Such a control mechanism may explain the lack of any correlation found in this study between either parity and socioeconomic status of the mother and neonatal hair trace metal concentrations.

Although sex has been reported to be an important covariate influencing the zinc, copper, manganese, and vanadium content of the hair of children and, in some cases, of adults $(6,7,19,20$, $27,30)$, no significant sex differences were noted for the metals in the neonatal hair samples in this study. It is possible that the requirements and utilization of trace metals for males and females differ only later in childhood $(27,33)$. Alternatively, the rigorous sampling procedures adopted in this study may have eliminated any sampling bias suggested as responsible for some of the differences noted by other investigators (11).

The positive correlation for zinc with manganese in the hair of the neonates suggests that the concentrations of these two elements at birth are interrelated. Baumslag et al. (5) demonstrated a significant relationship between zinc and copper levels in their neonatal hair samples. Reasons for these interrelationships are as yet unclear.

In view of the change that may occur in the hair trace metal levels during infancy and later childhood, comparisons of hair trace metal concentrations should be made strictly on an agerelated basis.

\section{COPPER}

The mean hair copper value (12.6 ppm) is closely comparable to the neonatal value (10.9 ppm) reported by Baumslag et al. (5), but slightly lower than the $15 \mathrm{ppm}$ reported by Strain et al. (31) for 15 neonates residing in Dayton, Ohio. These values are all lower than those reported for older children and young adults by Eads and Lambdin (10), Creason $e t$ al. (7), Schroeder and Nason (30), and Klevay (20). The range of values obtained in this study is large, and, in some cases, aberrant results correlate with elevated levels in maternal hair samples.

\section{ZINC}

The mean zinc concentration of these neonatal hair samples was similar $(224 \mathrm{ppm})$ to the value reported for neonates in Cincinnati (222 ppm) by Baumslag et al. (5) and Thai infants from upper socioeconomic homes (202 ppm) (17), although higher than those for Denver full term neonates (174 ppm), Denver infants (74 ppm) (16), and infants residing in Dayton, Ohio (138 ppm) (31). No source of external contamination can be identified to account for these differences. Regional differences in the trace metal content of the ground water may be responsible, in part, for these variations in neonatal hair zinc concentrations. Water supplies in Halifax County, Nova Scotia are acid and low in calcium (8). These factors enhance the utilization of zinc $(9,26)$.

\section{MANGANESE}

No comparable data exist for neonatal hair manganese levels although Hambidge and Baum (13) comment that newborn hair levels of manganese were not higher than hair concentrations of older children and adults. The mean, obtained in this study $(0.24$ ppm) was lower than that reported by Creason et al. (7) for New York children 0-5 yr (0.56 ppm). Studies of adults reveal even higher hair manganese concentrations ranging from 1 ppm $(7,10)$ to $3.1 \mathrm{ppm}(4)$.

Animal experiments have revealed that manganese levels in goat hair (1), sheep wool (21), and chicken feathers (24) vary significantly with manganese dietary intake, although no comparable investigation has been carried out in man.

\section{VANADIUM}

The distribution of vanadium in human tissues requires more extensive and critical investigation. Creason et al. (7) employing atomic absorption, reported hair vanadium levels in children $0-15$ yr as $0.20 \mathrm{ppm}$ for males and $0.37 \mathrm{ppm}$ for females, considerably higher than the neonatal hair concentrations $(0.05 \mathrm{ppm})$ found in this study. The low detection limit $(0.01 \mathrm{ppm})$ of the present vanadium determinations indicates that the very low hair values obtained in this study are real. The data of Creason et al. (7) suggest that the levels rise with increasing age as in the case of manganese and possibly copper.

\section{IODINE}

No other data for neonatal hair iodine concentrations have been found. The mean $(24.3 \mathrm{ppm})$ found in this study was slightly higher than the value (18.4 ppm) reported by Coleman et al. (6), for males representative of the population of England and Wales. Females were reported to have even lower values (12 ppm).

\section{CONCLUSION}

It is concluded, that, of the trace elements studied, neonatal hair concentrations of copper, manganese, and vanadium were lower than most reported values for older children and adults. In contrast, hair zinc concentrations at birth in this study were higher than values reported for neonates, infants, and younger children in Denver, although comparable to those values reported for Thai and English infants. Regional differences in the trace metal content of the ground water may be responsible, in part, for variations in neonatal hair zinc concentrations. These differences in turn may reflect higher body zinc concentrations in these patients. Changes in hair iodine concentrations with age are uncertain in view of the limited amount of data available.

\section{REFERENCES AND NOTES}

1. Anke, M.: Hair test to diagnose mineral deficiency. Veterinaermed.. 26: 445 (1971).

2. Bate, L. C.: Absorption and elution of trace elements on human hair: Intern. J. Appl. Radiation Isotopes, 17: 417 (1966).

3. Bate, L. C.: The use of activation analysis in procedures for the removal and characterization of the surface contaminants of hair. J. Forensic Sci., 10: 60 (1965).

4. Bate, L. C., and Dyer, F. F.: Trace elements in human hair. Nucleonics, 23: 74 (1965).

5. Baumslag, N., Yeager, D., Levin, L., Petering, H. G.: Trace metal content of maternal and neonate hair. Zinc, copper, iron and lead. Arch. Environ. Health, 29: $186(1974)$.

6. Coleman, R. F., Cripps, F. H., Stimson. A., and Scott, H. D.: The determination of trace elements in human hair by neutron activation and the application to forensic science. Report no. 0-86-66. p. 21 (Aldermaston, Atomic Weapons Research Establishment, 1966).

7. Creason, J. P., Hinners, T. A., Bumgarner, J. E., and Pinkerton, C.: Trace elements in hair as related to exposure in metropolitan New York, USA. Clin. Chem., 21: 603 (1975).

8. Cross, H. J.: Natural and manmade variations in ground water flow and chemistry in Birchcove and Sackville areas of Halifax County, Nova Scotia. (Unpublished M.Sc Thesis, Dalhousie University, 1975.)

9. Davis, G. K.: Factors influencing zinc availability in animals. In: A. Prasad: Zinc Metabolism. p. 215 (Charles C Thomas, Springfield, Illinois, 1966).

10. Eads, E. A., Lambdin, C. E.: A survey of trace metals in human hair. Environ. Res., 6: 247 (1973).

11. Hambidge, K. M.: Increase in hair copper concentration with increasing distance from the scalp. Am. J. Clin. Nutr., 26: 1212 (1973)

12. Hambidge, K. M.: Unpublished ohservations. 
13. Hambidge, K. M., and Baum, J. D.: Hair chromium concentrations of human newborn and changes during infancy. Am. J. Clin. Nutr., 25: 376 (1972).

14. Hambidge, K. M., Franklin, M. L., and Jacobs, M. A.: Changes in hair chromium concentrations with increasing distances from hair roots. Am. J. Clin. Nutr., 25: 380 (1972).

15. Hambidge, K. M., Franklin, M. L., and Jacobs, M. A.: Hair chromium concentrations: effects of sample washing and external environment. Am. J. Clin. Nutr., 25: 384 (1972).

16. Hambidge, K. M., and Walravens, P. A.: Zinc deficiency in infants and preadolescent children. In: A. S. Prasad: Trace Elements in Human Health and Disease. (Academic Press, New York, 1976.)

17. Hambidge, K. M., Walravens, P. A., Kumar, V., and Tuchinda, C.: Chromium, zinc, manganese, copper, nickel, iron, and cadmium concentrations in the hair of residents of Chandigarh, India and Bangkok. Thailand. In: D. Hemphill: Trace Substances in Environmental Health. p. 39. (Proc. 8th Ann. Conf. University of Missouri, Columbia, 1974.)

18. Harrison, W. W., Yurachek, J. P., and Benson, C. A.: The determination of trace elements in human hair by atomic absorption spectroscopy. Clin. Chim. Acta, 23: 83 (1969).

19. Klevay, L. M.: Hair as a biopsy material. I. Assessment of zinc nutriture. Am. J. Clin. Nutr., 23: 284 (1970)

20. Klevay, L. M.: Hair as a biopsy material. II. Assessment of copper nutriture. Am. J. Clin. Nutr., 23: 1194 (1970).

21. Lassiter, J. W., and Morton. J. D.: Effects of a low manganese diet on certain ovine characteristics. J. Animal Sci., 27: 776 (1968).

22. Lewis, P. K.. Jr., Hoekstra, W. G., and Grummer, R. H.: Restricted calcium feeding versus zinc supplementation for the control of parakeratosis in swine. J. Animal Sci., 16: 578 (1957).

23. Liebscher, K., and Smith, H.: Essential and nonessential trace elements: a method of determining whether an element is essential or nonessential in human tissue. Arch. Environ. Health, 17: 881 (1968).

24. Mathers, J. R., and Hill, R.: Manganese in the nutrition and metabolism of the pullet. 2. The manganese contents of the tissues of pullets given diets of high or low manganese content. Brit. J. Nutr., 22: 635 (1968).

25. Miller, W. J., Powell, G. W., Pitts, W. J., and Perkins, H. F.: Factors affecting

Copyright $\odot 1979$ International Pediatric Research Foundation, Inc.

$0031-3998 / 79 / 1309-0959 \$ 02.00 / 0$ zinc content of bovine hair. J. Dairy Sci., 48: 1091 (1965).

26. Oberleas, D., Muhere, M. E., and O'Dell, B. L.: The availability of zinc from foodstuffs. In: A. S. Prasad: Zinc Metabolism. p. 225 (Charles C Thomas, Springfield, Illinois, 1966).

27. Petering, H. G., Yeager, D. W., and Witherup, S. O.: Trace metal content of hair. I. Zinc and copper content of hair in relation to age and sex. Arch. Environ. Health, 23: 202 (1971).

28. Prasad, A. S.: Zinc deficiency in human subjects. In: A. S. Prasad: Zinc Metabolism. p. 250 (Charles C Thomas, Springfield, Illinois, 1966).

29. Routti, J.: Sampo, a Fortran IV Program for computer analysis of Gamma Spectra. p. 31 United States Government Publication no. UCRL-19452 (1969).

30. Schroeder, H. A., and Nason, P. A.: Trace metals in human hair. J. Invest. Dermatol., 53: 71 (1969).

31. Strain, W. H., Lascari, A., and Pories, W.: Zinc deficiency in babies. Proc. VIlth Int. Congress of Nutrition. p. 759 (1966).

32. Strain, W. H., Steadman, L. T., Lankau Jr., C. A., Berliner, W. P., and Pories, $W$. J.: Analysis of zinc levels in hair for the diagnosis of zinc deficiency in man. J. Lab. Clin. Med., 68: 244 (1966).

33. Walravens, P. A., Hambidge, K. M.: Growth of infants fed a zinc supplemented formula. Am. J. Clin. Nutr., 29: 1114 (1976)

34. Sherwood Medical Industries, St. Louis: Missouri, 63103. USA.

35. The authors thank Drs. D. C. Stuart and P. Jagan for their help with the activation procedures, the irradiations for which were carried out in the Slow Poke Facility of Dalhousie University. Dr. I. L. Gibson assisted with the data processing and Drs. J. C. L. Shaw and E. Palmer kindly read a preliminary version of the manuscript.

36. The present address of Rosalind S. Gibson is: Applied Human Nutrition, Department of Family Studies, University of Guelph, Guelph, Ontario, Canada, NIG 2W1.

37. This research was supported by a grant from the Izaak Walton Killam Hospital research fund, Halifax, Nova Scotia.

38. Requests for reprints should be addressed to: R. S. Gibson, B.Sc. MS, at the above address.

39. Received for publication May 8, 1978.

40. Accepted for publication August 21, 1978. 